\title{
REATIVIDADE DE ESCÓRIAS SILICATADAS DA INDÚSTRIA SIDERÚRGICA
}

\author{
Reactivity of silicate slags of the iron and steel industry \\ Hamilton Seron Pereira ${ }^{1}$, Ailton Junio Manzi Gama², \\ Mônica Sartori de Camargo ${ }^{3}$, Gaspar Henrique Korndorfer ${ }^{4}$
}

\begin{abstract}
RESUMO
As escórias siderúrgicas são usadas na agricultura, mas são poucos os trabalhos sobre sua reatividade. Neste trabalho, objetivou-se avaliar escórias siderúrgicas em diferentes frações granulométricas quanto à correção do pH e liberação de Ca, $\mathrm{Mg}$ e Si para o solo. O delineamento foi inteiramente casualizado com 4 repetições em esquema fatorial com 6 fontes (escória de alto-forno 1, escória de fosfato, escória de alto-forno 2, escória de aciaria de forno AOD, escória de aço inox e escória de forno LD) e 5 distribuições granulométricas $(2-1,41 ; 1,41-0,85 ; 0,85-0,50 ; 0,50-0,30 \mathrm{~mm} \mathrm{e}<0,30 \mathrm{~mm})$ e dois tratamentos adicionais (testemunha e $\mathrm{CaCO}_{3}$ ). $\mathrm{O} \mathrm{CaCO}_{3}$ foi usado como padrão para a determinação do índice de reatividade de cada escória. Foram aplicados $1500 \mathrm{mg} \mathrm{kg}^{-1}$ de equivalente $\mathrm{CaCO}_{3}$ e em todos os tratamentos e as doses de cada escória foram calculadas pelo seu PN-determinado. Houve aumento do $\mathrm{pH}$ com a redução do tamanho das partículas para todas as escórias. A escória de fosfato apresentou maior eficiência na liberação de $\mathrm{Ca}+\mathrm{Mg}$ em relação ao carbonato quando o tamanho das partículas foi menor que $0,5 \mathrm{~mm}$. Houve baixa eficiência na correção da acidez e liberação de $\mathrm{Ca}$ e $\mathrm{Mg}$ no solo nas.escórias de alto forno. Para maior liberação de silício, é necessário utilizar partículas de tamanho menor $(<0,3 \mathrm{~mm})$ para a escória de fosfato e de aço inox tamanhos intermediários $(0,85$ a 1,41), enquanto para a escória AOD e LD não há interferência da granulometria.
\end{abstract}

Termos para indexação: Escórias, silício, acidez, calcário.

\begin{abstract}
The slags are used in the agriculture as soil acidity correctives in same rates of lime, but there are few studies about its reactivity in soils. The objective was to compare slag reactivity to soil acidity correction and calcium, magnesium, and silicon liberation. A completely randomized experimental design was used, with 4 repetitions in factorial with 6 sources (blast furnace slag 1, phosphate slag, blast furnace slag 2, AOD furnace steel slag, stainless steel slag and LD furnace steel slag) and 5 particle sizes (2$1.41 ; 1.41-0.85 ; 0.85-0.50 ; 0.50-0.30 \mathrm{~mm}$ and $<0,30 \mathrm{~mm}$ ) and two additional treatments (control and $\mathrm{CaCO}_{3}$ ). $\mathrm{The}^{\mathrm{CaCO}} \mathrm{Cas}_{3}$ wased as a pattern for the determination of the reactivity index of each source. All treatments received $1500 \mathrm{mg} \mathrm{kg}^{-1} \mathrm{of}_{\text {equivalent } \mathrm{CaCO}_{3}}$ and each rate of slags was calculated by its determined neutralization power. The $\mathrm{pH}$-value increased with reduction of particle size in all slags. The phosphate slag showed best efficiency on the liberation of $\mathrm{Ca}+\mathrm{Mg}$ compared to the calcium carbonate in the granulometrics inferior to $0.5 \mathrm{~mm}$. There was low efficiency in soil acidity correction and liberation of the $\mathrm{Ca}$ and $\mathrm{Mg}$ in soil to slag of blast furnace. It is necessary to use particles smaller than $0.3 \mathrm{~mm}$ to improve silicon availability of phosphate slag and particles between 0.85 and $1.41 \mathrm{~mm}$ to stainless steel slag. The silicon availability of AOD furnace steel slag and LD furnace steel slag were not influenced by particle size.
\end{abstract}

Index terms: Slag, silicon, acidity, lime.

(Recebido em 12 de setembro de 2008 e aprovado em 14 de julho de 2009)

\section{INTRODUÇÃO}

O Brasil é o sexto maior produtor mundial de ferrogusa (25 milhões de toneladas), gerando, aproximadamente, 6,25 milhões de toneladas de escórias siderúrgicas a cada ano (Korndörfer et al., 2002). As escórias são resultantes de processamento em altas temperaturas, geralmente acima de $1400{ }^{\circ} \mathrm{C}$, quando a sílica presente como impurezas do minério ferroso reage com o calcário a ele adicionado como fundente. Esses subprodutos, resultantes da produção de ferro gusa em alto forno e de aço em forno de aciaria, são, assim, constituídos de silicatos de cálcio e magnésio e impurezas, com concentrações variáveis de acordo com o tipo de aço produzido (Coelho, 1998).

As escórias siderúrgicas já são usadas como corretivos de acidez nos Estados Unidos e Japão, apresentando, também, aumento na disponibilidade de silício, fósforo, cálcio e magnésio e redução na toxidez do ferro, manganês e alumínio no solo. A sua comercialização está prevista na legislação (Brasil, 2004), mas ainda é pouco explorada, em razão da dificuldade de sua moagem, provocando elevado desgaste e quebra das peças do

\footnotetext{
'Universidade Federal de Goiás/UFG - Campus de Jataí - Jataí, GO ${ }^{2}$ Clube Amigos da Terra/CAT - Uberlândia, MG

${ }^{3}$ APTA Regional Centro Sul - Cx. P.28 - 13412-050 - Piracicaba, SP - mscamarg@yahoo.com.br

${ }^{4}$ Universidade Federal de Uberlândia/UFU - Departamento de Ciências Agrárias - Uberlândia, MG
} 
moinho. Isso, no entanto, está mudando, com a recuperação do aço da escória por meio da moagem que apresenta alto valor econômico e a torna rica em silicato de $\mathrm{Ca}$ e $\mathrm{Mg}$ e livre de metais (Pereira et al., 2004).

Aliado a isso, o silicato apresenta uma maior solubilidade $\left(0,095 \mathrm{~g} \mathrm{dm}^{3}\right)$ que o carbonato de cálcio $(0,014$ $\mathrm{g} \mathrm{dm}^{3}$ ) (Alcarde, 1992). Como o carbonato de cálcio com granulometria abaixo de 50 mesh $(<0,3 \mathrm{~mm})$ reage $100 \%$ no solo após três meses, provavelmente, o silicato de cálcio poderia ter o mesmo comportamento com granulometrias maiores que 50 mesh. Apesar da maior solubilidade do silicato, o processo industrial promove a obtenção de vários tipos de escórias, com recristalização diferente em função da quantidade de $\mathrm{Ca}, \mathrm{Mg}$ e do tempo de resfriamento, podendo reduzir sua solubilidade.

A solubilidade do Si nas fontes depende do tipo de ligação química que esse elemento forma, conforme mostraram Medina-Gonzales et al. (1988), incubando o ortosilicato de di-cálcio $\left(\mathrm{Ca}_{2} \mathrm{SiO}_{4}\right)$ e o metasilicato de cálcio $\left(\mathrm{CaSiO}_{3}\right)$. De modo geral, as fontes de silício na forma de silicato ligado a um cátion têm sido as de maior solubilidade e disponibilidade de Si às plantas, sendo os silicatos com cátions monovalentes (silicato de sódio e silicato de potássio) as fontes mais solúveis, seguidas dos silicatos bivalentes (silicato de $\mathrm{Ca}$ e silicato de $\mathrm{Mg}$ ).

Há grande variação na composição e disponibilidade de Si das escórias. Takahashi (1981) mostrou que a disponibilidade de Si era maior em escórias com lento resfriamento ao ar, em relação àquelas esfriadas em água. Constatou, também, que a disponibilidade de Si aumentou com a redução no tamanho das partículas.

Dentre os fatores que influenciam a eficiência agronômica dos corretivos, destacam-se a quantidade, o teor de equivalente carbonato, o tempo de contato com o solo e a granulometria (Piau, 1991; Amaral Sobrinho et al., 1993; Oliveira et al., 1994; Novais et al., 1995). A granulometria mais fina permite uma maior reatividade com o solo, em razão da maior superfície de contato da partícula da escória com o solo (Novais et al., 1995). Trabalhando com escórias siderúrgicas de alto forno, Oliveira et al. (1994) demonstraram que as partículas menores são mais eficientes no fornecimento de $\mathrm{Ca}$ e $\mathrm{Mg}$ para o solo que as mais grosseiras.

Conduziu-se este trabalho, com o objetivo de avaliar escórias siderúrgicas em diferentes frações granulométricas quanto à correção do pH e liberação de $\mathrm{Ca}, \mathrm{Mg}$ e Si para o solo.

\section{MATERIAL E MÉTODOS}

O trabalho foi realizado em casadevegetação da Universidade Federal de Uberlândia, utilizando-se amostras (0-20 cm) de Latossolo Vermelho distrófico (LVd) (Tabelas 1 e 2). A sua caracterização física foi feita de acordo com o método proposto pela Embrapa (1999) e os teores de $\mathrm{SiO}_{2}, \mathrm{Al}_{2} \mathrm{O}_{3}, \mathrm{Fe}_{2} \mathrm{O}_{3}$, para o horizonte $\mathrm{A}$ dos solos, foram obtidos (Tabela 2) pelo ataque sulfúrico (Vettori, 1969). A análise química para fins de rotina foi feito pelo método descrito pela Comissão de Fertilidade do Solo do Estado de Minas Gerais-CFSEMG (1999) e o Si pelo cloreto de cálcio 0,01 mol L-1 (Camargo et al., 2008).

$\mathrm{O}$ delineamento experimental foi inteiramente casualizado com quatro repetições, em esquema fatorial $6 \mathrm{x}$ 5, com 6 escórias siderúrgicas (escória de alto-forno 1 da Mannesmam; escória de fosfato da Rhodia (EUA); escória de alto-forno 2 da Companhia Siderúrgica Nacional-CSN; escória de aciaria de forno pelo processo descarbonetação argônio-oxigênio (AOD) da Acesita; escória de aço inox da Recmix; escória de forno LD da Açominas) e cinco frações granulométricas (entre 2 - 1,41; 1,41 - 0,85; 0,85 - 0,50; 0,50 $0,30 \mathrm{~mm}$ e $<0,30 \mathrm{~mm}$ ) e dois tratamentos adicionais, uma testemunha e um tratamento com $\mathrm{CaCO}_{3}$ p.a., totalizando assim 32 tratamentos. O tratamento com $\mathrm{CaCO}_{3}$ foi usado como padrão de comparação na dose de $1500 \mathrm{mg} \mathrm{kg}^{-1}$, sendo que nos demais tratamentos as doses também foram 1500 mg kg-1 de equivalente $\mathrm{CaCO}_{3}$, calculadas pelo poder de neutralização (PN) determinado (CFSEMG, 1999) de cada fonte (Tabela 3). Essa dose foi calculada para elevar a saturação por bases (V\%) a apenas $25 \%$. Isso foi feito porque o objetivo foi verificar a velocidade de reação das escórias, evitando-se um aumento excessivo do $\mathrm{pH}$ se fossem utilizadas doses elevadas, além de uma redução da reatividade, principalmente das frações mais finas.

Após isso, esse material foi acondicionado em potes (250 g), que permaneceram fechados, segundo o método descrito por Medina-González et al. (1988). A umidade do solo foi mantida a $80 \%$ da capacidade de campo utilizandose água destilada (sem silício). Após 90 dias, que é o tempo padrão para o cálculo de reatividade dos calcários, amostras dos solos foram retiradas dos potes, secas ao ar e submetidas às análises de $\mathrm{pH}\left(\mathrm{CaCl}_{2}\right)$, cálcio e magnésio extraído por KCl $1 \mathrm{~mol} \mathrm{~L}^{-1}$ (CFSEMG, 1999) e silício solúvel em ácido acético 0,5 $\mathrm{mol} \mathrm{L}^{-1}$ (Korndörfer et al., 1999).

Por meio dos resultados de $\mathrm{pH}$ e $\mathrm{Ca}+\mathrm{Mg}$, foi calculado o índice de eficiência agronômica (IEA), adaptado de modelo sugerido por Raij (1991) e aqui denominado índice de reatividade (IR) onde: $\mathrm{IR}(\%)=[$ (Y2$\mathrm{Y} 0) /(\mathrm{Y} 1-\mathrm{Y} 0)$ ] x100, onde $\mathrm{Y} 0=$ valores obtidos pelas parcelas sem corretivos; Y1 = valores obtidos usando o corretivo padrão (1500 mg kg-1 de $\left.\mathrm{CaCO}_{3}\right)$; Y2 = valores obtidos com a mesma dose de equivalente $\mathrm{CaCO}_{3}$ das fontes testadas nas diferentes tamanhos de partículas. 
Tabela 1 - Características físicas e mineralógicas do solo utilizado.

\begin{tabular}{cccccccccc}
\hline Solo & Argila & Silte & Areia Grossa & Areia Fina & $\mathrm{SiO}_{2}$ & $\mathrm{Al}_{2} \mathrm{O}_{3}$ & $\mathrm{Fe}_{2} \mathrm{O}_{3}$ & $\mathrm{Ki}$ & $\mathrm{Kr}$ \\
\hline LVd & 820 & 70 & 60 & 50 & 18,1 & 31,4 & 9,5 & 0,98 & 0,82 \\
\hline
\end{tabular}

Tabela 2 - Características químicas do solo utilizado no experimento.

\begin{tabular}{|c|c|c|c|c|c|c|c|c|c|c|c|c|}
\hline $\mathrm{pH}$ & $\mathrm{Si}$ & $\mathrm{P}^{1}$ & $\mathrm{~K}$ & $\mathrm{Al}$ & $\mathrm{Ca}$ & $\mathrm{Mg}$ & $\mathrm{H}+\mathrm{Al}$ & $\mathrm{t}^{2}$ & $\mathrm{~T}^{3}$ & $\mathrm{~V}^{4}$ & $\mathrm{~m}^{5}$ & MO \\
\hline $\mathrm{CaCl}_{2}$ & \multicolumn{2}{|c|}{$-\mathrm{mg} \mathrm{kg}{ }^{-1}$} & & \multicolumn{6}{|c|}{$\mathrm{mmol}_{\mathrm{c}} \mathrm{dm}^{-3}$} & \multicolumn{2}{|c|}{-----\%----- } & $\mathrm{g} \mathrm{kg}^{-1}$ \\
\hline 4,4 & 38 & 2 & 0,6 & 7 & 2,0 & 0,4 & 70 & 10 & 73 & 4,1 & 70 & 40 \\
\hline
\end{tabular}

${ }^{1}$ Mehlich-I; ${ }^{2} \mathrm{CTC}$ efetiva; ${ }^{3} \mathrm{CTC} \mathrm{pH} 7,00 ;{ }^{4}$ saturação por bases; ${ }^{5}$ saturação por alumínio.

Tabela 3 - Características químicas dos materiais utilizados.

\begin{tabular}{cclcccr}
\hline Materiais & Origem & $\mathrm{Ca}$ & $\mathrm{Mg}$ & $\begin{array}{c}\mathrm{PN} \\
\text { calculado }\end{array}$ & $\begin{array}{c}\text { PN } \\
\text { determinado }\end{array}$ & DOSE \\
\hline Alto-forno 1 (AF1) & Mannesmam & 215 & 45,1 & 725 & 700 & $\begin{array}{c}\text { Eq. } \mathrm{maCO}_{3}, \mathrm{~g} \mathrm{~kg}^{-1} \\
\text { Alto-forno 2(AF2) }\end{array}$ \\
Escória de fosfato & RSN & 304 & 31,4 & 891 & 875 & 1706 \\
Escória aciaria AOD & Acesita & 311 & 4,1 & 795 & 630 & 2369 \\
Escória de Aço Inox & Recmix & 262 & 34,7 & 1152 & 1185 & 1259 \\
Escória de aciaria LD & Açominas & 197 & 17,6 & 891 & 875 & 1706 \\
$\mathrm{CaCO}_{3}$ & p.a. & 423 & 1,3 & 564 & 915 & 1631 \\
\hline
\end{tabular}

A análise estatística das variáveis $\mathrm{pH}\left(\mathrm{CaCl}_{2}\right), \mathrm{Ca}, \mathrm{Mg}$ e Si incluiu a análise de variância pelo teste $\mathrm{F}$ (Tabela 4). Para avaliar o efeito entre as escórias, aplicou-se o teste Tukey e para o efeito do tamanhos de partículas e o índice de reatividade de cada escória, efetuou-se a regressão polinomial.

\section{RESULTADOS E DISCUSSÃO}

Não houve efeito significativo entre a testemunha e o carbonato apenas para o $\mathrm{Mg}$ e $\mathrm{Si}$ do solo, sendo as demais variáveis analisadas significativas (Tabela 5). Essa não significância entre os valores para a testemunha e o carbonato é decorrente da ausência desses elementos nesses tratamentos.

Houve aumento do $\mathrm{pH}$ do solo com a redução do tamanho das partículas para todas as escórias (Figura 1). A aplicação do $\mathrm{CaCO}_{3}$ proporcionou a maior elevação de $\mathrm{pH}$, o que era esperado por se tratar de produto muito fino e puro (PA). Nas frações contendo partículas menores (frações 0,50-0,85 e 0,30-0,50mm), a escória de fosfato, de acidaria e de aço inox foram as mais reativas, enquanto nas maiores (1,41-2mm e 1,41-0,85 mm) a escória de fosfato não apresentou valor de $\mathrm{pH}$ tão alto quanto às anteriormente citadas. Embora as doses das escórias tenham sido niveladas pelo equivalente $\mathrm{CaCO}_{3}$, a sua solubilidade numa mesma granulometria foi diferente entre elas, o que pode ser explicado pela diferença de cristalização de cada material. Esses dados indicam que essas escórias podem substituir o calcário quanto à sua capacidade de neutralizar a acidez do solo desde que aplicadas na dose em função do seu equivalente em $\mathrm{CaCO}_{3}$.

Tabela 4 - Quadro de variância aplicado aos tratamentos.

\begin{tabular}{clc}
\hline Item & Causas de variação & GL \\
\hline 1 & Testemunha x $\mathrm{CaCO}_{3}$ & 1 \\
2 & Testemunha x variáveis (escórias e frações) & 1 \\
3 & $\mathrm{CaCO}_{3}$ x variáveis (escórias e frações) & 1 \\
4 & Escórias & 5 \\
5 & Frações & 4 \\
6 & Escórias x Frações & 20 \\
\hline 7 & Tratamento & 32 \\
8 & Resíduo & 95 \\
\hline 9 & Total & 127 \\
\hline
\end{tabular}


Tabela 5 - Valores de F do quadro de análise de variância aplicado aos tratamentos.

\begin{tabular}{ccccc}
\hline Causas de variação & $\mathrm{pH}$ & $\mathrm{Ca}$ & $\mathrm{Mg}$ & $\mathrm{Si}$ \\
\hline Testemunha x $\mathrm{CaCO}_{3}$ & $143,23^{* *}$ & $309,48^{* *}$ & $0,74^{\mathrm{ns}}$ & $1,31^{\mathrm{ns}}$ \\
Testemunha x variáveis (escórias, tamanho) & $89,58^{* *}$ & $137,07^{* *}$ & $92,94 * *$ & $46,10^{* *}$ \\
$\mathrm{CaCO}_{3}$ x variáveis (escórias, tamanho) & $51,63^{* *}$ & $162,99 * *$ & $117,42^{* *}$ & $27,04^{* *}$ \\
Escórias & $119,61^{* *}$ & $294,57^{* *}$ & $716,73^{* *}$ & $103,00^{* *}$ \\
Tamanho de partículas & $101,39 * *$ & $181,01^{* *}$ & $263,71^{* *}$ & $26,28^{* *}$ \\
Escórias x Tamanho de partículas & $5,72^{*}$ & $14,60^{* *}$ & $38,36^{* *}$ & $9,60^{* *}$ \\
\hline Tratamento & $43,83^{* *}$ & $96,83^{* *}$ & $175,52^{* *}$ & $27,71^{* *}$ \\
\hline C.V. $\%$ & 1,88 & 8,86 & 9,50 & 19,92 \\
\hline
\end{tabular}
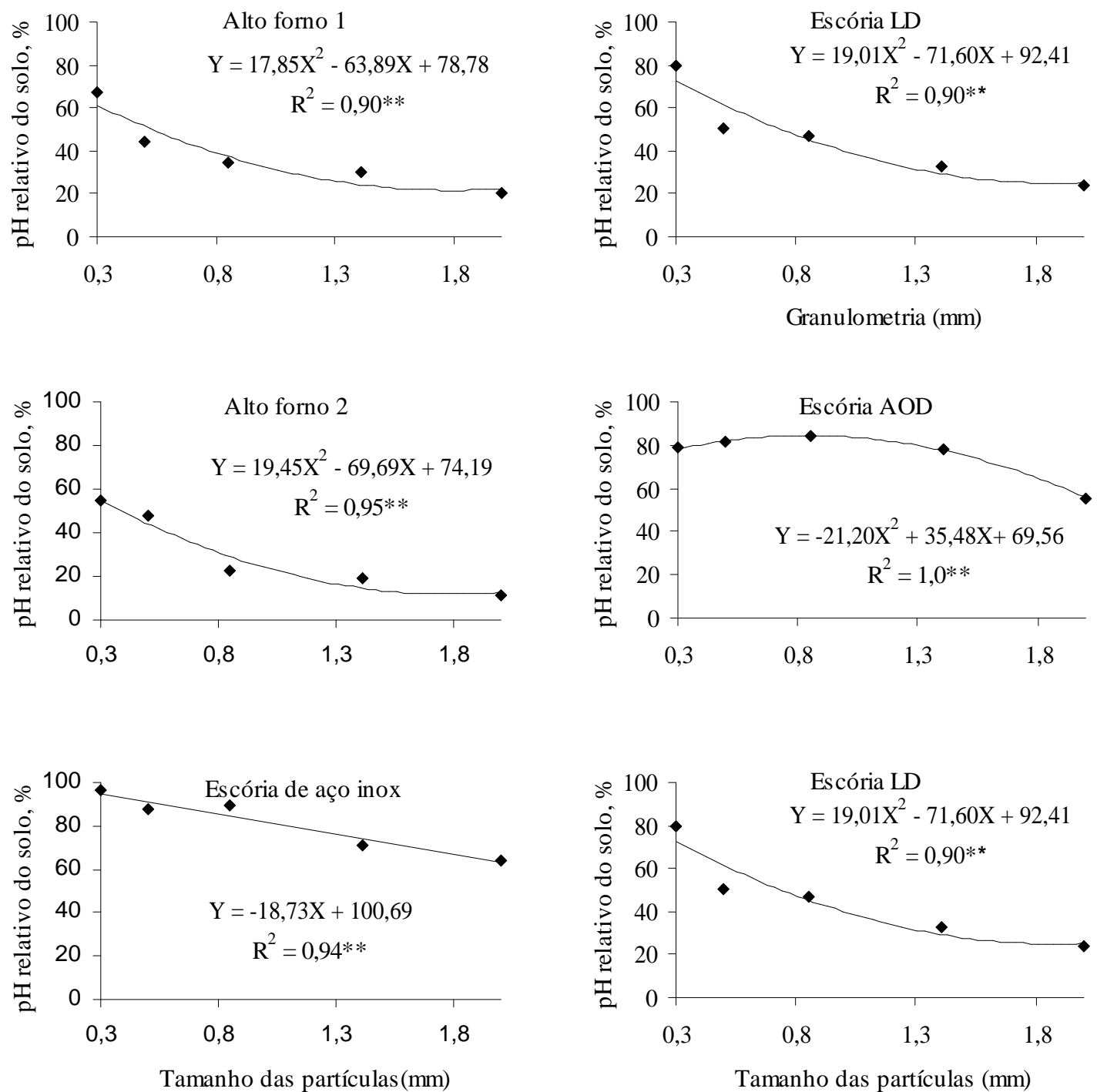

Figura 1 - Efeito do tamanho de partículas dos resíduos no valor de pH relativo em relação ao carbonato de cálcio $(* * \mathrm{p}<0,01)$ 
As escórias de alto-forno, principalmente a AF2, apresentaram menor reatividade, indicando a baixa solubilidade dessas escórias, que atingiram um máximo de $60 \%$ do $\mathrm{pH}$ relativo ao padrão $\mathrm{CaCO}_{3}$ (Figura 1). Resultados semelhantes foram obtidos em 1989 por Rocha e Fuinhas (Pereira et al., 2004) que verificaram que todas as escórias estudadas elevaram o $\mathrm{pH}$ do solo, sendo as provenientes de aciaria (FEA, LD e AOD) as mais eficientes, seguidas do calcário e de alto forno e de ferro/ níquel. Resultado intermediário foi obtido para escória de fosfato e de forno LD, diferindo da escórias de aço inox e forno AOD nas maiores granulometrias, mas não nas mais finas (Tabela 6)
Assim como ocorreu com o $\mathrm{pH}$, o maior teor de $\mathrm{Ca}$ foi verificado no tratamento com $\mathrm{CaCO}_{3}$ (Tabela 7), que diferiu pelo teste $\mathrm{F}$ dos demais tratamentos (Tabela 5). A escória de fosfato, de aciaria AOD e aço inox apresentaram maiores teores de cálcio quando o tamanho das partículas foi maior (frações 0,85-1,41 e 1,41-2,00). Em frações menores a escória de fosfato foi superior às demais. As fontes de alto forno (AF1 e AF2), por sua vez, apresentaram o menor teor em cálcio em todas as frações (Tabela 7). Isso concorda com Oliveira et al. (1994), que obtiveram maior eficiência no fornecimento de $\mathrm{Ca}$ e $\mathrm{Mg}$ com tamanho de partículas menores que $0,3 \mathrm{~mm}$, enquanto as maiores que $2 \mathrm{~mm}$ foram menos efetivas. Novais et al.

Tabela 6 - Valor de pH no solo após 90 dias de incubação.

\begin{tabular}{|c|c|c|c|c|c|c|}
\hline \multirow[t]{2}{*}{ Materiais } & \multicolumn{5}{|c|}{ Tamanho de partículas $(\mathrm{mm})^{1}$} & \multirow[b]{2}{*}{ Média } \\
\hline & 1,41 a 2 & 0,85 a 1,41 & 0,50 a 0,85 & 0,30 a 0,50 & $<0,30$ & \\
\hline & \multicolumn{5}{|c|}{ "--------------------------------pH------------------------------------- } & \\
\hline Alto-forno 1 (AF1) & $4,61 b$ & $4,71 \mathrm{C}$ & $4,77 \mathrm{bc}$ & $4,87 \mathrm{~b}$ & $5,13 b c$ & $4,82 \mathrm{c}$ \\
\hline Alto-forno 2 (AF2) & $4,51 b$ & $4,59 \mathrm{C}$ & $4,64 \mathrm{c}$ & $4,91 \mathrm{~b}$ & $4,99 \mathrm{c}$ & $4,73 d$ \\
\hline Escória de fosfato & $4,61 b$ & $4,99 \mathrm{~B}$ & $5,24 \mathrm{a}$ & $5,43 \mathrm{a}$ & $5,34 \mathrm{a}$ & $5,12 b$ \\
\hline Escória aciaria AOD & $5,00 \mathrm{a}$ & $5,25 \mathrm{~A}$ & $5,32 \mathrm{a}$ & $5,29 a$ & $5,26 a b$ & $5,22 \mathrm{a}$ \\
\hline Escória de Aço Inox & $5,10 \mathrm{a}$ & $5,18 \mathrm{Ab}$ & $5,37 \mathrm{a}$ & $5,36 \mathrm{a}$ & $5,46 a$ & $5,29 a$ \\
\hline Escória de aciaria LD & $4,64 b$ & $4,75 \mathrm{C}$ & $4,90 \mathrm{~b}$ & $4,95 b$ & $5,27 \mathrm{ab}$ & $4,90 \mathrm{c}$ \\
\hline $\mathrm{DMS}^{2} 5 \%$ & \multicolumn{5}{|c|}{-------------------------0,19-------------------------- } & 0,09 \\
\hline Testemunha & & & & & & 4,38 \\
\hline $\mathrm{CaCO}_{3}$ & & & & & & 5,50 \\
\hline
\end{tabular}

${ }^{1}$ Médias seguidas pela mesma letra na coluna não diferem significativamente pelo teste Tukey a 5\% de probabilidade

${ }^{2}$ Diferença mínima significativa das médias.

Tabela 7 - Teor de cálcio no solo após 90 dias de incubação.

\begin{tabular}{|c|c|c|c|c|c|c|}
\hline \multirow[t]{2}{*}{ Fonte } & \multicolumn{5}{|c|}{${\text { Tamanho de partículas }(\mathrm{mm})^{1}}^{1}$} & \multirow[b]{2}{*}{ Média } \\
\hline & 1,41 a 2 & 0,85 a 1,41 & 0,50 a 0,85 & 0,30 a 0,50 & $<0,30$ & \\
\hline & \multicolumn{6}{|c|}{ 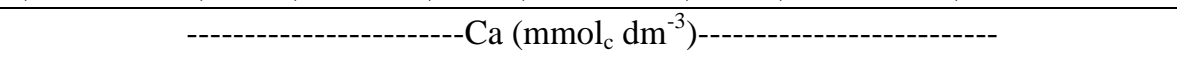 } \\
\hline Alto-forno 1 (AF1) & $4,3 b$ & $5,5 b c$ & $6,9 \mathrm{~d}$ & $8,6 \mathrm{~d}$ & $12,1 \mathrm{~cd}$ & $7,5 \mathrm{~d}$ \\
\hline Alto-forno 2 (AF2) & $4,0 \mathrm{~b}$ & $4,5 \mathrm{c}$ & $6,0 \mathrm{~d}$ & $7,9 \mathrm{~d}$ & $10,5 d$ & $6,6 \mathrm{e}$ \\
\hline Escória de fosfato & $9,5 \mathrm{a}$ & $12,0 \mathrm{a}$ & $17,1 \mathrm{a}$ & $21,5 \mathrm{a}$ & $20,0 \mathrm{a}$ & $16,0 \mathrm{a}$ \\
\hline Escória aciaria AOD & $11,0 \mathrm{a}$ & $12,6 \mathrm{a}$ & $13,5 b$ & $15,1 b$ & $14,1 \mathrm{bc}$ & $13,3 b$ \\
\hline Escória de Aço Inox & $9,7 \mathrm{a}$ & $13,4 \mathrm{a}$ & $14,7 \mathrm{~b}$ & $13,0 \mathrm{c}$ & $13,8 b c$ & $12,9 b$ \\
\hline Escória de aciaria LD & $5,8 \mathrm{~b}$ & $7,2 \mathrm{~b}$ & $9,3 \mathrm{c}$ & $8,4 \mathrm{~d}$ & $14,6 b$ & $9,1 \mathrm{c}$ \\
\hline $\mathrm{DMS}^{2} 5 \%$ & \multicolumn{5}{|c|}{ 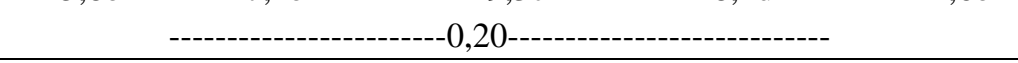 } & 0,9 \\
\hline Testemunha & & & & & & 2,8 \\
\hline $\mathrm{CaCO}_{3}$ & & & & & & 19,7 \\
\hline
\end{tabular}


(1995) também mostraram que foi necessária maior quantidade de escória de alto forno com tamanho de partículas maior $(2,0 \mathrm{~mm})$ em relação às menores $(0,3 \mathrm{~mm})$ para a mesma produção de matéria seca de Eucalyptus urophylla.

A diferença nos teores de $\mathrm{Ca}$ do solo entre as escórias aplicadas ocorreu, em razão da diferença do seu teor nesses materiais (Tabela 3). A escória de aciaria AOD e aço inox, mesmo na fração com tamanho de partículas maiores(1,41-2 mm), apresentaram elevada liberação de Ca para o solo. A escória de fosfato apresenta, também, valores próximos às escórias de aciaria AOD e aço inox, mas o teor de Ca dessa fonte nessa fração granulométrica foi menor que $50 \%$ do Ca liberado pelas fração com partículas menores que $0,30 \mathrm{~mm}$, sem descontar o $\mathrm{Ca}$ inicial do solo (Tabela 7). Assim, as escórias de alto-forno e aciaria de forno LD apresentaram menor correção do $\mathrm{pH}$ e menor liberação no $\mathrm{Ca}$, com aumento da granulometria (Figura 2).

Quanto ao magnésio, a escória proveniente de aço inox foi superior na sua liberação em todas as granulometrias, resultado esperado em razão da sua maior concentração (Tabela 8). Depois da escória de aço inox, os maiores teores de magnésio foram obtidos para as escórias de alto forno (AF 1 e AF 2), sem diferença significativa entre si nas granulometrias, com exceção naquela menor que $0,30 \mathrm{~mm}$. Isso se deve à maior concentração desse elemento na AF1 em relação a escória AF2 (Tabela 3). A escória de fosfato e de forno AOD, por sua vez, apresentaram a menor disponibilidade de $\mathrm{MG}$, em razão da sua baixa concentração.
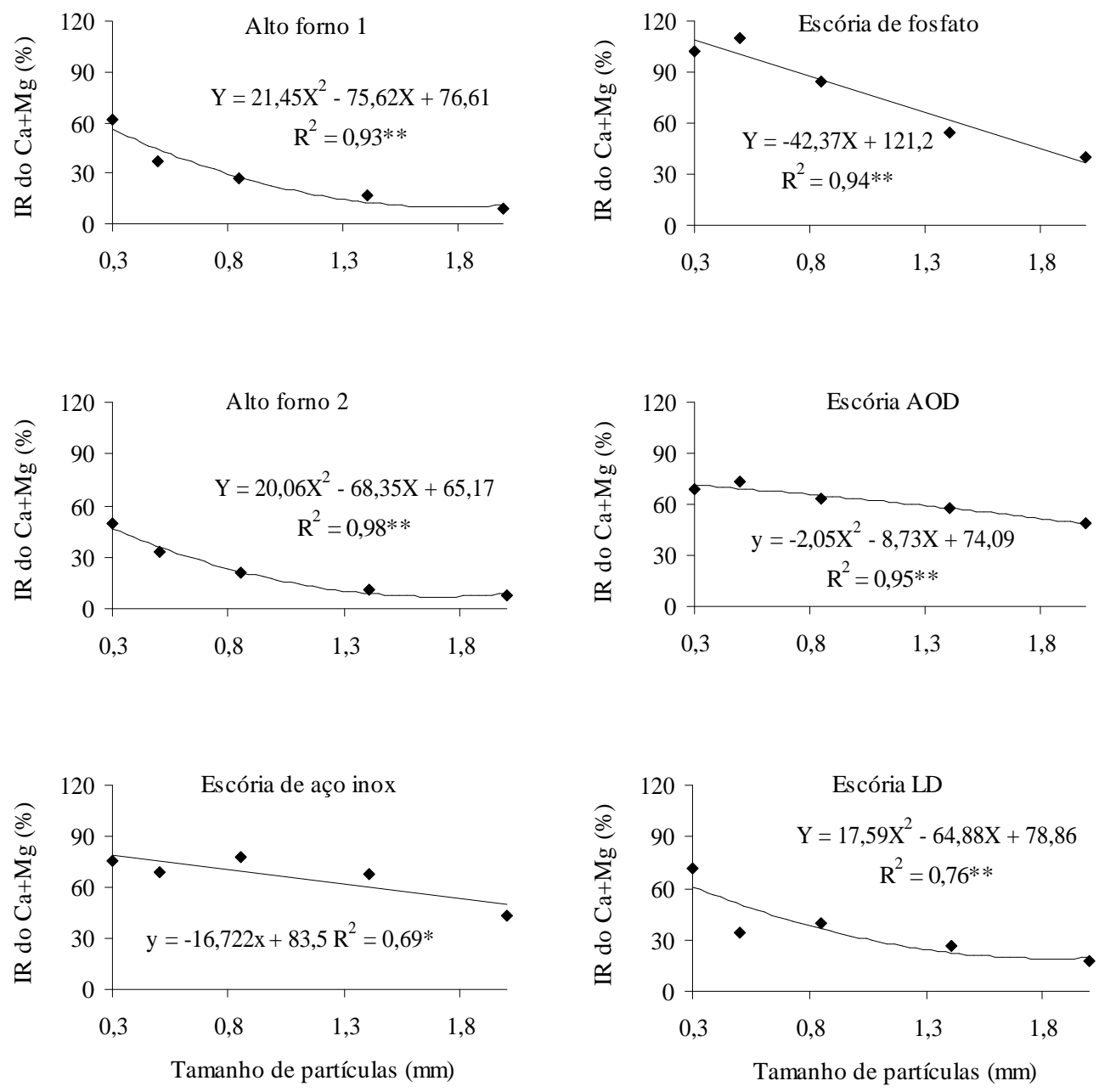

Figura 2 - Efeito do tamanho de partículas das escórias na liberação relativa de $\mathrm{Ca}+\mathrm{Mg}$ no solo (** p<0,01). 
Tabela 8 - Teor de magnésio no solo após 90 dias de incubação.

\begin{tabular}{|c|c|c|c|c|c|c|}
\hline \multirow[t]{2}{*}{ Materiais } & \multicolumn{5}{|c|}{ 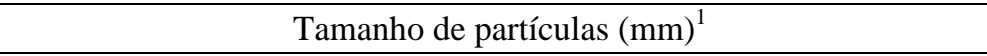 } & \multirow[b]{2}{*}{ Média } \\
\hline & 1,41 a 2 & 0,85 a 1,41 & 0,50 a 0,85 & 0,30 a 0,50 & $<0,30$ & \\
\hline & \multicolumn{6}{|c|}{ - } \\
\hline Alto-forno 1 (AF1) & $0,50 \mathrm{bc}$ & $0,56 \mathrm{~B}$ & $0,73 b$ & $0,86 \mathrm{~b}$ & $1,45 b$ & $0,82 \mathrm{~b}$ \\
\hline Alto-forno 2 (AF2) & $0,52 \mathrm{~b}$ & $0,55 \mathrm{~b}$ & $0,65 b$ & $0,82 b$ & $0,99 \mathrm{c}$ & $0,71 \mathrm{c}$ \\
\hline Escória de fosfato & $0,41 b c$ & $0,42 \mathrm{Bc}$ & $0,39 \mathrm{c}$ & $0,40 \mathrm{~d}$ & $0,41 \mathrm{e}$ & $0,41 \mathrm{e}$ \\
\hline Escória aciaria AOD & $0,36 \mathrm{c}$ & $0,36 \mathrm{C}$ & $0,38 \mathrm{c}$ & $0,44 \mathrm{~d}$ & $0,76 \mathrm{~d}$ & $0,46 \mathrm{e}$ \\
\hline Escória de Aço Inox & $0,72 \mathrm{a}$ & $1,24 \mathrm{~A}$ & $1,71 \mathrm{a}$ & $1,81 \mathrm{a}$ & $2,14 \mathrm{a}$ & $1,52 \mathrm{a}$ \\
\hline Escória de aciaria LD & $0,37 \mathrm{c}$ & $0,45 \mathrm{Bc}$ & $0,62 b$ & $0,59 \mathrm{c}$ & $0,71 d$ & $0,55 \mathrm{~d}$ \\
\hline $\mathrm{DMS}^{2} 5 \%$ & & ------------- & $----0,15----$ & ----- & & 0,07 \\
\hline Testemunha & & & & & & 0,40 \\
\hline $\mathrm{CaCO}_{3}$ & & & & & & 0,36 \\
\hline
\end{tabular}

${ }^{1}$ Médias seguidas pela mesma letra na coluna não diferem significativamente pelo teste Tukey a 5\% de probabilidade

${ }^{2}$ Diferença mínima significativa das médias.

De modo geral, o aumento na granulometria reduziu a liberação de $\mathrm{Mg}$, conforme ocorreu com o $\mathrm{Ca}$ (Figura 2). Como as concentrações de $\mathrm{Ca}$ e $\mathrm{Mg}$ das escórias são diferentes, os resultados em conjunto poderiam expressar melhor a eficiência agronômica das escórias, uma vez que eles definem o poder de neutralização e as doses aplicadas. Assim, considerando o teor de $\mathrm{Ca}+\mathrm{Mg}$, a única fonte que apresentou valores superiores a $100 \%$ foi a escória de fosfato nas frações granulométricas com partículas menores que $0,5 \mathrm{~mm}$. As demais escórias proporcionaram resultados inferiores àqueles apresentados pelo carbonato de cálcio (Figura 2).

Por ser um produto puro e de granulometria menor, o carbonato foi mais reativo, mas é importante ressaltar que a reação no solo do silicato é diferente do carbonato. As escórias de alto forno apresentaram baixa reatividade (60\%), mesmo em granulometria menor que $0,3 \mathrm{~mm}$. Assim, para correção igual ao calcário, é necessária moagem mais fina da escória. $\mathrm{O}$ aumento do valor de $\mathrm{pH}$ e concentração de $\mathrm{Cae} \mathrm{Mg}$ com menor granulometria concordam com Prado et al. (2004).

O teor de silício no solo aumentou com a aplicação das escórias, sendo diferente entre eles e nas frações granulométricas estudadas (Tabela 9, Figura 3). Esse aumento de Si do teor de Si inicial do solo e os alcançados com os tratamentos é decorrente do alto poder de extração do ácido acético $0,5 \mathrm{~mol} \mathrm{~L}^{-1}$ (Pereira et al., 2004). Para as escórias de alto forno, houve redução linear no teor de silício extraído pelo ácido acético à medida que o tamanho das partículas aumentou (Figura 3). Ao contrário disso, para as escórias de fosfato e de aço inox, as equações quadráticas indicam que houve maior liberação em partículas de tamanhos intermediários. Para a escória AOD e LD, a utilização das diversas frações granulométricas, não interferiram na quantidade de silício extraída pelo ácido acético.

O comportamento diferenciado de escórias de siderurgia é decorrente do seu material de origem. As escórias de alto forno, que são menos reativas (Pereira et al., 2004), apresentaram elevada liberação de Si em tamanhos de partículas menores (Figura 3), indicando o maior ataque do ácido acético a esses materiais nessa granulometria. As fontes mais reativas liberaram Si em menor quantidade extraída pelo ácido acético. Embora um dos inconvenientes do ácido acético seja sua grande extração de silício nas escórias de alto forno, conforme mostrado por Pereira et al. (2004), os resultados do presente experimento indicam que ele diferenciou a redução na liberação de $\mathrm{Si}$ no solo com o aumento do tamanho das partículas para esse tipo de escória. Assim, para maior liberação de silício ao solo pela escória de alto forno é necessária a utilização de partículas de tamanho menor $(<0,3 \mathrm{~mm})$ e para a escória de fosfato e de aço inox, tamanhos intermediários $(0,85$ a 1,41). Ao contrário disso, escória AOD e LD podem ser utilizadas em qualquer granulometria com a mesma quantidade de silício liberada ao solo. 
Tabela 9 - Teor de silício no solo após 90 dias de incubação.

\begin{tabular}{|c|c|c|c|c|c|c|}
\hline \multirow[t]{3}{*}{ Materiais } & \multicolumn{5}{|c|}{ Tamanho de partículas (mm) } & \multirow[b]{2}{*}{ Média } \\
\hline & 1,41 a 2 & 0,85 a 1,41 & 0,50 a 0,85 & 0,30 a 0,50 & $<0,30$ & \\
\hline & & & $---\mathrm{Si}(\mathrm{mg}$ & & & \\
\hline Alto-forno 1 (AF1) & $59 b$ & $89 b$ & $149 \mathrm{ab}$ & $159 b$ & $203 a$ & $132 b$ \\
\hline Alto-forno 2 (AF2) & $71 b$ & $162 \mathrm{a}$ & $190 \mathrm{ab}$ & $240 \mathrm{a}$ & $251 \mathrm{a}$ & $183 a$ \\
\hline Escória de fosfato & $165 a$ & $189 \mathrm{a}$ & $175 \mathrm{ab}$ & $169 b$ & $121 b$ & $164 \mathrm{a}$ \\
\hline Escória aciaria AOD & $51 b$ & $65 b$ & $60 \mathrm{c}$ & $59 \mathrm{c}$ & $58 \mathrm{~d}$ & $59 \mathrm{c}$ \\
\hline Escória de Aço Inox & $80 \mathrm{~b}$ & $112 b$ & $136 b$ & $121 b$ & $111 b c$ & $112 b$ \\
\hline Escória de aciaria LD & $47 b$ & $69 b$ & $63 \mathrm{c}$ & $56 \mathrm{c}$ & $70 \mathrm{~cd}$ & $61 \mathrm{c}$ \\
\hline $\mathrm{DMS}^{2} 5 \%$ & & -------০---০--- & $----48,2---$ & --------------- & & 21,6 \\
\hline Testemunha & & & & & & 38 \\
\hline $\mathrm{CaCO}_{3}$ & & & & & & 57 \\
\hline
\end{tabular}

${ }^{1}$ Médias seguidas pela mesma letra na coluna não diferem significativamente pelo teste Tukey a 5\% de probabilidade

${ }^{2}$ Diferença mínima significativa das médias.
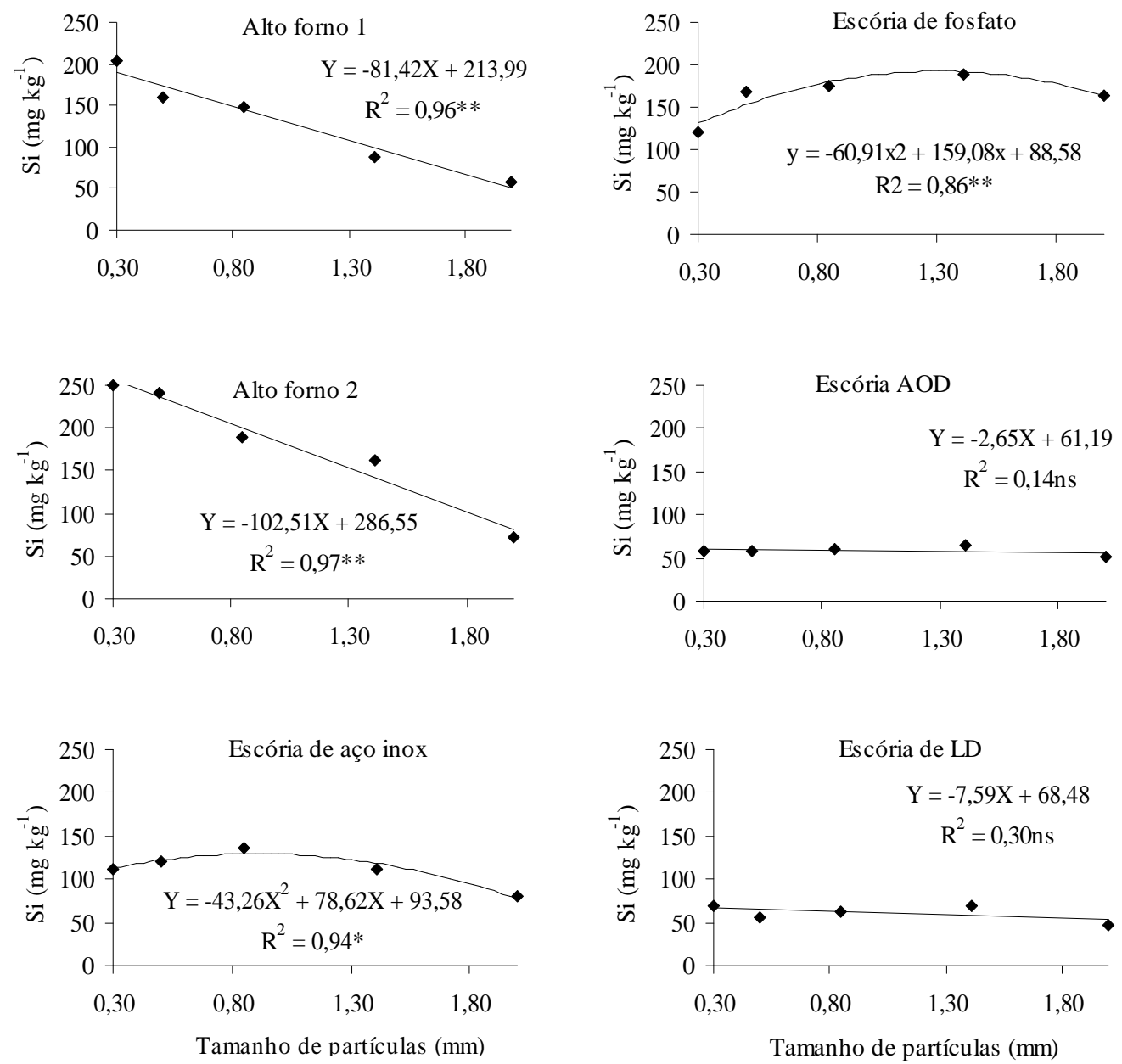

Figura 3 - Efeito do tamanho de partículas das escórias no teor de silício do solo $(* *$ p $<0,01 ; p<0,05$; ns=não significativo). 


\section{CONCLUSÃO}

As escórias siderúrgicas aplicadas em doses baixas aumentaram o pH, Ca e Mg do solo com a redução da granulometria, sendo as de aciaria mais eficientes em todas as granulometrias e as de alto forno de baixa reatividade.

Para maior liberação de silício ao solo, com a utilização de baixas doses de escórias de siderurgia, é necessária a utilização de partículas de tamanho menor ( $<0,3 \mathrm{~mm}$ ), para a escória de fosfato e de aço inox tamanhos intermediários $(0,85$ a 1,41$)$, enquanto que, para a escória AOD e LD, não há interferência da granulometria.

\section{REFERÊNCIAS BIBLIOGRÁFICAS}

ALCARDE, J.C. Corretivos da acidez dos solos: características e interpretações técnicas. São Paulo: ANDA, 1992. 26p. (Boletim técnico, 6).

AMARAL SOBRINHO, N.M.B.; COSTA, L.M.; DIAS, L.E.; BARROS, N.F. Aplicação de resíduo siderúrgico em um Latossolo: efeitos na correção do solo e na disponibilidade de nutrientes e metais pesados. Revista Brasileira de Ciência do Solo, Viçosa, v.17, n.1, p.271-276, 1993.

BRASIL. Decreto $\mathbf{N}^{0}$ 2954. Aprova o regulamento da lei $\mathrm{n}^{0}$ 6894 de 16 de janeiro de 1980, que dispõe sobre a inspeção e fiscalização da produção e do comércio de fertilizantes, corretivos, inoculantes ou biofertilizantes destinados à agricultura, e dá outras providências. Brasília, 14 jan. 2004.

CAMARGO, M.S. de; KORNDÖRFER, G.H.; PEREIRA, H.S. Solubilidade do silício em solos: influência do calcário e ácido silícico aplicados. Bragantia, Campinas, v.66, n.4, p.637-647, 2007.

COELHO, P.E. Da escória ao vidro. Revista de Limpeza Pública, São Paulo, v.49, p.36-45, 1998.

\section{COMISSÃO DE FERTILIDADE DO SOLO DO ESTADO DE MINAS GERAIS. Recomendações para o uso de corretivos e fertilizantes em Minas Gerais: $4^{\mathrm{a}}$ aproximacão. Lavras, 1989. 159p.}

\section{EMPRESA BRASILEIRA DE PESQUISA} AGROPECUÁRIA. Manual de análises químicas de solos, plantas e fertilizantes. Brasília: Embrapa Comunicação para Transferência de Tecnologia, 1999. 370p.

KORNDÖRFER, G.H.; COELHO,N.M.; SNYDER, G.H.; MIZUTANI, C.T. Avaliação de métodos de extração de silício para solos cultivados com arroz de sequeiro.
Revista Brasileira de Ciência do Solo, Viçosa, v.23, n.1, p.101-106, 1999.

KORNDORFER, G.H.; PEREIRA, H.S.; CAMARGO, M.S. Silicatos de cálcio e magnésio na agricultura. Uberlândia: GPSi-ICIAG-UFU, 2002. 23p. (Boletim Técnico, 1).

MEDINA-GONZALES, O.A.; FOX, R.L.; BOSSHART, R.P. Solubility and availability to sugarcane (Saccharum spp.) of two silicate materials. Fertilizer Ressearch, The Haghe, v.16, n.1, p.3-13, 1988.

NOVAIS, R.F.; BARROS, N.F.; FIRME, D.J.; LEITE, F.P.; VILLANI, E.M.A.; TEIXEIRA, J.L.; LEAL, P.G.L. Eficiência agronômica de escórias de siderurgia. In: CONGRESSO BRASILEIRO DE CIÊNCIA DO SOLO, 25., 1995, Viçosa. Anais... Viçosa: SBCS, 1995. v.4, p.2282-2284.

OLIVEIRA, A.C.; HAHNE, H.; BARROS, N.F.; MORAIS, E.J. Uso de escória de alto forno como fonte de nutrientes na adubação florestal. In: SEMINÁRIO SOBRE USO DE RESÍDUOS FLORESTAIS E URBANOS EM FLORESTAS, 1994, Botucatu. Anais... Botucatu: Fundação de Estudos e Pesquisas Agrícolas e Florestais, 1994. p.77-96.

PEREIRA, H.S.; KORNDORFER, G.H.; VIDAL, A. de A.; CAMARGO, M.S. de. Silicon sources for rice crop. Scientia Agricola, Piracicaba, v.61, n.5, p.522-528, 2004.

PIAU, W.C. Viabilidade do uso de escórias como corretivo e fertilizantes. 1991. 99f. Dissertação (Mestrado em Energia Nuclear na Agricultura)-Escola Superior de Agricultura "Luiz de Queiroz”, Universidade de São Paulo, Piracicaba, 1991.

PRADO, R.M.; NATALE, W.; FERNANDES, F.M.; CORREAA, M.C.M. Reatividade de uma escória de siderurgia em um Latossolo Vermelho distrófico. Revista Brasileira de Ciência do Solo, Viçosa, v.28, n.1, p.197-205, 2004.

RAIJ, B. van. Fertilidade do solo e adubação. Piracicaba: Agronômica Ceres; Associação Brasileira para a Pesquisa da Potassa e do Fosfato, 1991. 343p.

TAKAHASHI, K. Effect of slags on growth and silicon uptake by rice plants and the available silicates in paddy soils. Bulletin of the Shikoku Agricultural Experiment Station, Kagawa, n.38, p.75-114, 1981.

VETTORI, L. Métodos de análises de solos. Rio de Janeiro: Ministério da Agricultura, 1969. 24p. (Boletim Técnico, 7). 